University of New Hampshire

University of New Hampshire Scholars' Repository

$10-2011$

\title{
Children's Exposure to Intimate Partner Violence and Other Family Violence.
}

Sherry L. Hamby

The University of the South - Sewanee

David Finkelhor

University of New Hampshire - Main Campus, David.Finkelhor@unh.edu

Heather Turner

University of New Hampshire - Main Campus, Heather.Turner@unh.edu

Richard Ormrod

University of Northern Colorado

Follow this and additional works at: https://scholars.unh.edu/ccrc

Part of the Domestic and Intimate Partner Violence Commons

\section{Recommended Citation}

Sherry L. Hamby, David Finkelhor, Heather A. Turner, \& Richard K. Ormrod. Children's exposure to intimate partner violence and other forms of family violence: Nationally representative rates among US youth. OJJDP Juvenile Justice Bulletin - NCJ 232272, pgs. 1-12. Washington, DC: US Government Printing Office.

This Article is brought to you for free and open access by the Research Institutes, Centers and Programs at University of New Hampshire Scholars' Repository. It has been accepted for inclusion in Crimes Against Children Research Center by an authorized administrator of University of New Hampshire Scholars' Repository. For more information, please contact Scholarly.Communication@unh.edu. 


\section{Children's Exposure to Intimate Partner Violence and Other Family Violence}

\author{
Sherry Hamby, David Finkelhor, Heather Turner, \\ and Richard Ormrod
}

This bulletin discusses the data on exposure to family violence in the National Survey of Children's Exposure to Violence (NatSCEV), the most comprehensive nationwide survey of the incidence and prevalence of children's exposure to violence to date, sponsored by the Office of Juvenile Justice and Delinquency Prevention (OJJDP) and the Centers for Disease Control and Prevention (CDC) (see "History of the National Survey of Children's Exposure to Violence," p. 2). An earlier bulletin (Finkelhor, Turner, Ormrod, Hamby, and Kracke, 2009) presented an overview of children's exposure to conventional crime, child maltreatment, other types of physical and sexual assault, and witnessing community violence. For more information on the survey methodology, see "Methodology," p. 5.

This bulletin explores in depth the NatSCEV survey results regarding exposure to family violence among children in the United States, including exposure to intimate partner violence (IPV), assaults by parents on siblings of children surveyed, and other assaults involving teen and adult household members. These results confirm that children are exposed to unacceptable rates of violence in the home. More than 1 in 9 (11 percent) were exposed to some form of family violence in the past year, including 1 in 15 (6.6 percent) exposed to IPV between parents (or between a parent and that parent's partner). One in four children (26 percent) were exposed to at least one form of family violence during their lifetimes. Most youth exposed to family violence, including 90 percent of those exposed to IPV, saw the violence, as opposed to hearing it or other indirect forms of exposure. Males were more likely to perpetrate incidents that were witnessed than females, with 68 percent of youth witnessing only violence by males. Father figures were the most common perpetrators of family violence, although assaults by mothers and other caregivers were also common. Children often witness family violence, and their needs should be assessed when incidents occur. These are the most comprehensive and detailed data ever collected at the national level on this topic.
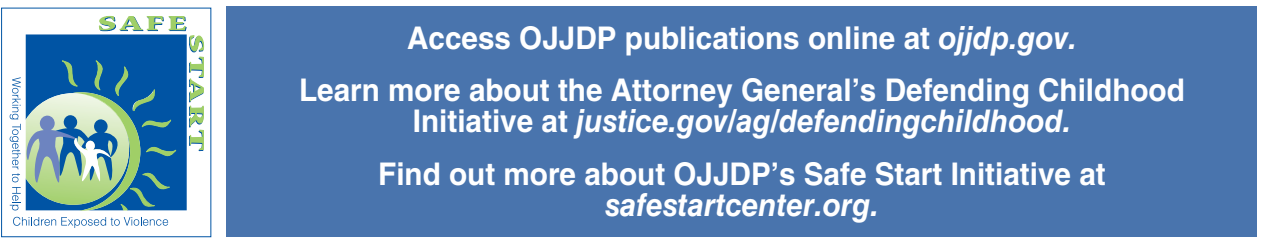

\section{A Message From OJJDP}

Children are exposed to violence every day in their homes, schools, and communities. Such exposure can cause them significant physical, mental, and emotional harm with long-term effects that can last well into adulthood.

The Attorney General launched Defending Childhood in September 2010 to unify the Department of Justice's efforts to address children's exposure to violence under one initiative. Through Defending Childhood, the Department is raising public awareness about the issue and supporting practitioners, researchers, and policymakers as they seek solutions to address it. A component of Defending Childhood, OJJDP's Safe Start Initiative continues efforts begun in 1999 to enhance practice, research, training and technical assistance, and public education about children and violence.

Under Safe Start, OJJDP conducted the National Survey of Children's Exposure to Violence, the most comprehensive effort to date to measure the extent and nature of the violence that children endure and its consequences on their lives. This is the first study to ask children and caregivers about exposure to a range of violence, crime, and abuse in children's lives.

As amply evidenced in this bulletin series, children's exposure to violence is pervasive and affects all ages. The research findings reported here and in the other bulletins in this series are critical to informing our efforts to protect children from its damaging effects. 


\section{Background}

Exposure to IPV is distressing to children and is associated with a host of mental health symptoms both in childhood and in later life. The best documented mental health effects include symptoms of posttraumatic stress, depression, and anxiety (Kitzmann et al., 2003; Lang and Stover, 2008; Wolfe et al., 2003). Exposure to serious IPV as a child is also associated with offending as an adult. For example, one study found that, among a sample of IPV offenders, those who had as a child seen a parent use a weapon were more likely to commit an offense involving a weapon as an adult (Murrell et al., 2005). Despite the well-documented adverse consequences of IPV exposure and a growing discussion of the appropriate policy responses to IPV exposure (Jaffe, Crooks, and Wolfe, 2003; Nixon et al., 2007), surprisingly little information is available about how often such exposure occurs in the general population. Such information is important for determining the extent of the problem, assessing the need for services, and establishing a baseline for evaluating progress.

\section{Previous Efforts To Estimate Children's Exposure to Family Violence}

More than 20 years ago, in the second National Family Violence Survey (conducted in 1985), Straus and Gelles asked adults whether they had witnessed IPV during their childhood; they obtained a rate of 13 percent for total childhood exposure (Straus, 1992). McDonald and colleagues (2006) estimated IPV exposure at 15.5 million U.S. youth by calculating the number of children in two-parent homes where IPV had occurred. This measure was indirect, however, as some children may not have been aware of these incidents, especially the types of IPV most commonly reported in national surveys (i.e., one or two incidents of pushes and slaps) (Straus and Gelles, 1990; Tjaden and Thoennes, 1998).

The Developmental Victimization Survey (DVS) ${ }^{1}$ included a single item on witnessing IPV (Finkelhor et al., 2005), which produced a 1-year incidence rate of 3 percent. Although this is probably the best existing estimate of 1-year incidence, it is well established that single items in surveys often underrepresent the true extent of violence (Bolen and Scannapieco, 1999). This percentage also counted only events that children saw, excluding other forms of exposure such as hearing or seeing evidence of the attack afterwards.

\section{History of the National Survey of Children's Exposure to Violence}

Under the leadership of then-Deputy Attorney General Eric Holder in June 1999, the Office of Juvenile Justice and Delinquency Prevention (OJJDP) created the Safe Start Initiative to prevent and reduce the impact of children's exposure to violence. As a part of this initiative and with a growing need to document the full extent of children's exposure to violence, OJJDP launched the National Survey of Children's Exposure to Violence (NatSCEV) with the support of the Centers for Disease Control and Prevention.

NatSCEV is the first national incidence and prevalence study to comprehensively examine the extent and nature of children's exposure to violence across all ages, settings, and timeframes. Conducted between January and May 2008, it measured the past-year and lifetime exposure to violence for children age 17 and younger across several major categories: conventional crime, child maltreatment, victimization by peers and siblings, sexual victimization, witnessing and indirect victimization (including exposure to community violence and family violence), school violence and threats, and Internet victimization. This survey marks the first comprehensive attempt to measure children's exposure to violence in the home, school, and community across all age groups from birth to age 17 , and the first attempt to measure the cumulative exposure to violence over the child's lifetime. The survey asked children and their adult caregivers about not only the incidents of violence that children suffered and witnessed themselves but also other related crime and threat exposures, such as theft or burglary from a child's household, being in a school that was the target of a credible bomb threat, and being in a war zone or an area where ethnic violence occurred.

The study was developed under the direction of OJJDP and was designed and conducted by the Crimes Against Children Research Center of the University of New Hampshire. It provides comprehensive data on the full extent of violence in the daily lives of children. The primary purpose of NatSCEV is to document the incidence and prevalence of children's exposure to a broad array of violent experiences across a wide developmental spectrum. The research team asked followup questions about specific events, including where the exposure to violence occurred, whether injury resulted, how often the child was exposed to a specific type of violence, and the child's relationship to the perpetrator and (when the child witnessed violence) the victim. In addition, the survey documents differences in exposure to violence across gender, race, socioeconomic status, family structure, region, urban/rural residence, and developmental stage of the child; specifies how different forms of violent victimization "cluster" or co-occur; identifies individual, family, and community-level predictors of exposure to violence among children; examines associations between levels/types of exposure to violence and children's mental and emotional health; and assesses the extent to which children disclose incidents of violence to various individuals and the nature and source of any assistance or treatment provided.

Most recently, Zinzow and colleagues (2009) obtained a lifetime estimate of 9 percent in the National Survey of Adolescents-Replication (NSA-R), but their sample included only adolescents and included only violence between parents. Further, they assessed only severe forms of physical violence, so in many ways their estimate is less comparable to most national data on IPV, which typically include a wide range of acts. Both the DVS and the NSA-R were also limited to the most direct forms of exposure (seen and seen or heard, respectively), and did not assess the relative frequency of different forms of exposure. Other estimates on exposure to family violence come from high-risk convenience samples, such as women residing in domestic violence shelters. Not surprisingly, exposure percentages are often high in these settings, frequently exceeding 50 percent (Hutchison and Hirschel, 2001), but they do not provide a picture of the national extent of the problem. Many of these studies collect data on only one parental relationship (often the mother or other primary caregiver and her current partner), but in today's world, children may have multiple parents, stepparents, and other caregivers and are at risk for being exposed to violence between many family members. NatSCEV is one of the first studies to assess exposure for all key relationships in a child's life. 


\section{Important Features of Family Violence Incidents}

In addition to annual incidence and lifetime prevalence estimates, NatSCEV also provides the first nationally representative data on certain characteristics of IPV exposure that have been of interest to those concerned about the problem.

Type of exposure. Many authors have pointed out that children can be exposed to IPV in multiple ways. Although as many as 10 different types of exposure have been identified (Holden, 2003), some of the most commonly mentioned include seeing and hearing violent acts, seeing injuries resulting from the violence, and being told about the violence. Usually these are arranged hierarchically. The most direct forms of exposure are seeing or direct eyewitnessing, which may also include lower levels of exposure such as hearing. Seeing the violence implies the child's presence, which may also put the child in danger, and is least subject to errors in interpretation. A child could also hear violence but not see it, for example, if the child is in another room in the house or apartment. This means the child was nearby during the assault, and so potentially in danger, but hearing is less likely to be accurate than seeing. For example, youth could mistakenly attribute violence heard on television to their parents, or, conversely, they might not hear an assault even though they are in the house or apartment where the assault occurs.

Youth can also become aware of violence after it occurs, for example, by seeing the victim's injuries afterwards. This type of exposure will usually be fairly contemporaneous with the assault because most injuries eventually heal. Finally, youth could be told about the assault after it occurs, even years after the incident. Several authors have suggested that these types of exposure other than direct eyewitness exposure make up a significant proportion of children's total exposure to family violence (Fantuzzo and Mohr, 1999; Holden, 2003); however, no nationally representative data on type of exposure have previously been collected.

Gender of perpetrator. There has been keen interest in gender patterns of IPV perpetration (Hamby, 2009), particularly whether women's participation in IPV deserves clinical and policy attention. Data from witnessed events are important both for examining gender patterns in family violence and for characterizing children's experience of gender-related aggression. Studies that assess the gender of the perpetrator of witnessed IPV find that males perpetrate most family violence, but females also can be aggressors. In the DVS, males perpetrated 86 percent of the IPV incidents that were witnessed and 67 percent of the witnessed incidents of physical abuse of a sibling (Hamby, Ormrod, and Finkelhor, 2005). Straus found that one-half (50 percent) of youth exposed to family violence reported that only their fathers were violent, 31 percent reported that both parents were perpetrators, and 19 percent reported that only their mothers were perpetrators (Straus, 1992). NatSCEV provides an opportunity to explore this issue using a larger sample with more items and, as a result, generate more reliable estimates of gender patterns of family violence (see "Screening Questions: Exposure to Intimate Partner Violence and Other Family Violence," p. 9).

Reaction to incident. Finally, the nature of children's involvement in IPV episodes has been a topic of interest (Edleson, Shin, and Armendariz, 2008). The safety plans of many organizations recommend that parental victims of family violence teach their children how to seek help or get to safety during an attack (National Domestic Violence Hotline, 1998), but little information exists about how frequently they do this. One survey of police incidents revealed that 11 percent of calls to police were made by youth exposed to family violence (Fantuzzo et al., 1997). In a clinical sample, more than one-half of youth had yelled at their parents during a fight or tried to get away from the fighting (Edleson, Shin, and Armendariz, 2008). The current study includes an assessment of three responses: yelling, seeking help, and trying to get away.

\section{Findings From the NatSCEV Study Regarding Children's Exposure to IPV and Other Family Violence}

The purpose of this bulletin is to report the first comprehensive, nationally representative estimates of youth's exposure to IPV and other violence within the family. It presents information regarding types of exposure, the gender of the perpetrator, the relationship of the child witness to the perpetrator, and youth's reactions to the incident. It then discusses the implications of the survey data for researchers, practitioners, and policymakers and makes policy recommendations, including better screening protocols for exposure to family violence, improved interventions for those exposed, increased coordination of services for adult and child victims of family violence, and more prevention and education programs to reduce family violence.

\section{Percentages of Exposure to IPV and Other Family Violence}

Table 1 shows the percentages of pastyear and lifetime exposure to various forms of family violence for NatSCEV survey participants across both genders and four age groups: ages $0-5,6-9$, 10-13, and 14-17. The researchers looked at exposure to psychological violence between parents (threats and displaced aggression), physical violence between parents (including hitting or slapping or more serious violence, such as one parent kicking, choking, or beating up the other), and violence involving other family members (a parent hitting another child in the family or a grownup or teen in the family assaulting another family member). The researchers then aggregated the data to determine total past-year and lifetime percentages for exposure to psychological/ emotional IPV between parents, physical IPV between parents, and any exposure to family violence.

Past-year exposure percentages. Approximately 1 in 15 youth, or 6.6 percent, had been exposed to some form of physical assault between their parents in the past year. A roughly equivalent percentage, 5.7 percent, was exposed to psychological/ emotional IPV (verbal threats, punching walls, and throwing, breaking, or destroying household items) in the past year. If exposure to other forms of family violence is included, such as parental assaults on other children or assaults between teen or adult relatives in the household, then one in nine youth (11.1 percent) were exposed to physical or psychological violence in the family during the previous year. Not surprisingly, the most severe violence (one parent kicking, choking, or beating up the other) had the lowest exposure percentage (1.3 percent), while displaced aggression, including seeing a parent break something, punch a wall, or throw things, was reported most often (4.9 percent). 
Table 1. Nationally Representative Percentages of Exposure to Family Violence and Abuse: Past-Year and Lifetime Percentages for Total Sample and by Youth Gender and Age

\begin{tabular}{|c|c|c|c|c|c|c|c|}
\hline & & Gen & outh & & & & \\
\hline & Total & Male & Female & $0-5$ & 6-9 & 10-13 & $14-17$ \\
\hline Item & 4,549 & 2,331 & 2,219 & 1,458 & 1,041 & 1,037 & 1,014 \\
\hline
\end{tabular}

Exposure to Intimate Partner Violence (interparental)

1. Verbal threat

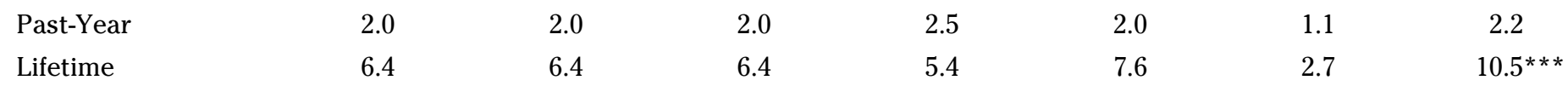

2. Displaced aggression (broke something, punched wall, or threw things)
Past-Year
4.9
4.8
5.0
6.7
3.8
2.3
$6.2^{* * *}$
Lifetime
15.2
14.2
16.1
11.5
13.7
11.5
$25.5^{* * *}$

3. Eyewitness to assault of parent

\begin{tabular}{|c|c|c|c|c|c|c|c|}
\hline Past-Year & 2.6 & 2.4 & 2.9 & 3.2 & 1.6 & 2.3 & 3.2 \\
\hline Lifetime & 11.7 & 11.2 & 12.3 & 7.1 & 10.0 & 11.4 & $20.6^{* * *}$ \\
\hline
\end{tabular}

4. Pushed

\begin{tabular}{|c|c|c|c|c|c|c|c|}
\hline Past-Year & 3.9 & 3.7 & 4.0 & 5.1 & 2.9 & 3.4 & $3.7^{*}$ \\
\hline Lifetime & 13.7 & 13.2 & 14.2 & 10.5 & 12.9 & 11.0 & $22.0^{* * *}$ \\
\hline
\end{tabular}

5. Hit or slapped

$\begin{array}{lrrrrrrc}\text { Past-Year } & 2.4 & 2.1 & 2.6 & 3.6 & 1.4 & 1.9 & 2.1^{\text {** }} \\ \text { Lifetime } & 10.1 & 9.9 & 10.4 & 8.2 & 10.5 & 8.0 & 14.7^{\text {*** }}\end{array}$

6. Severe physical (kicked, choked, or beat up)

\begin{tabular}{|c|c|c|c|c|c|c|c|}
\hline Past-Year & 1.3 & 1.2 & 1.4 & 1.6 & 0.8 & 1.4 & 1.2 \\
\hline Lifetime & 5.3 & 5.2 & 5.5 & 4.6 & 5.7 & 4.0 & $7.3^{* *}$ \\
\hline
\end{tabular}

7. Parental assault of sibling

$\begin{array}{lllllllc}\text { Past-Year } & 1.8 & 1.7 & 1.9 & 1.6 & 0.9 & 2.1 & 2.9^{* *} \\ \text { Lifetime } & 4.6 & 4.9 & 4.3 & 2.5 & 2.4 & 4.4 & 10.3^{* * *}\end{array}$

8. Other family violence (Grownup or teen pushed, hit, or beat up another relative)

$\begin{array}{llllllll}\text { Past-Year } & 3.4 & 3.1 & 3.7 & 3.0 & 2.3 & 2.6 & 5.9^{* * *} \\ \text { Lifetime } & 7.8 & 7.4 & 8.3 & 4.5 & 6.9 & 5.7 & 15.8^{* * *}\end{array}$

Aggregate Percentages

Any exposure to psychological/emotional IPV (1 and 2 above)

\begin{tabular}{|c|c|c|c|c|c|c|}
\hline Past-Year & 5.7 & 5.5 & 6.5 & 6.5 & 5.2 & 3.9 \\
\hline Lifetime & 16.0 & 14.7 & $17.4^{\dagger}$ & 11.8 & 15.6 & 11.8 \\
\hline
\end{tabular}

Any exposure to physical IPV $(3,4,5$, and 6 above)

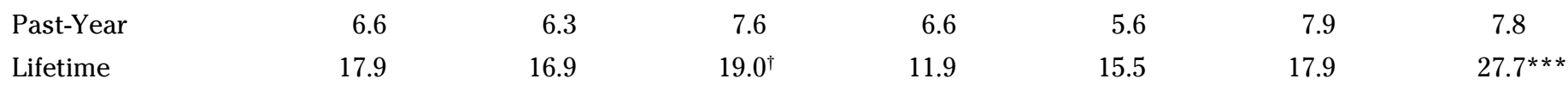

Any exposure to any family violence (1 through 8 above)
Past-Year
11.1
10.5
11.7
10.2
9.0
11.4
$13.8^{* *}$
Lifetime
25.6
24.8
26.4
17.2
22.8
24.0
$40.3^{* * *}$

Note: Weighted $n$; detail may not add to total due to rounding. Age differences are significant for ${ }^{*} p<.05 ;{ }^{* \star} p<.01 ;{ }^{* \star} p<.001$. Gender differences are significant for ${ }^{\dagger} p<.05$

$\mathrm{IPV}=$ Intimate partner violence. 


\section{Methodology}

The National Survey of Children's Exposure to Violence (NatSCEV) was conducted between January and May 2008. Researchers conducted interviews about the experiences of a nationally representative sample of 4,549 children and adolescents age 17 and younger. They interviewed by telephone youth ages 10 to 17 and adult caregivers of children age 9 and younger. Evidence shows that because telephone interviews afford greater anonymity and privacy than in-person interviews, they can encourage those interviewed to be more forthcoming about such sensitive matters as being exposed to violence or being victims of crime (Acierno et al., 2003; Shannon et al., 2007). The interview and analysis sample $(n=4,549)$ consisted of two groups: a nationally representative sample of telephone numbers within the contiguous United States $(n=3,053)$ and an oversample of telephone exchanges with 70 percent or greater African American, Hispanic, or low-income households to ensure a proportion of minority and low-income households large enough for subgroup analysis. Both groups were sampled through random-digit dialing. The cooperation rate for the first group was 71 percent and the response rate was 54 percent. The oversample had somewhat lower cooperation (63 percent) and response rates (43 percent). A nonresponse analysis conducted on households that could not be contacted or that declined to participate indicated that the risk of victimization for those households did not differ systematically from the risk for households that took part in the survey. An adult, usually a parent, provided demographic information for each participating household, including race/ethnicity (one of four categories: white, non-Hispanic; black, non-Hispanic; other race, nonHispanic; and Hispanic, any race) and household income. The child in the household with the most recent birthday was then selected to be surveyed. Interviewers spoke directly with children age 10 and older; for children age 9 and younger, the parent or other adult caregiver "most familiar with the child's daily routine and experience" was interviewed. Comparison of a number of indicators, including reports of child maltreatment or neglect and violence by family members, found no evidence that caregivers who answered for younger children failed to report neglect or violence that was occurring in the family. Comparison of proxy and self-reports using this instrument also found little evidence of reporter bias (Finkelhor et al., 2005; Finkelhor, Turner, Ormrod, and Hamby, 2009). Past studies have similarly found that caregivers are at least as likely as youth to disclose incidents of family violence (Grych, 1998; Jouriles and Norwood, 1995). Interviews averaged about 45 minutes in length and were conducted in both English and Spanish. Approximately 279 caregiver interviews were conducted in Spanish; almost all interviews with children and adolescents age 10 and older were in English.

\section{Survey Assessment of Exposure to Family Violence}

To determine rates of exposure to family violence, eight types of victimization were assessed: seeing, hearing, or otherwise learning of a parent being assaulted by a spouse, domestic partner, or boyfriend or girlfriend; seeing, hearing, or otherwise learning of a threat by one parent to assault the other; seeing, hearing, or otherwise learning of a threat by one parent to damage the other parent's property; seeing, hearing, or otherwise learning of one parent pushing the other; seeing, hearing, or otherwise learning of one parent hitting or slapping the other; seeing, hearing, or otherwise learning of one parent kicking, choking, or beating up the other; seeing a brother or sister assaulted by a parent; and witnessing an assault by another adult household member against a child or adult in the household. The researchers collected data on past-year and lifetime exposure to each of these types of family violence and categorized them by gender and age group. They then aggregated that data to create total scores for any exposure to emotional/psychological intimate partner violence (IPV), physical IPV, and any exposure to family violence.

In addition, the researchers asked followup questions relating to how the survey participants were exposed to family violence (whether they saw the incident, heard the incident, saw injuries resulting from the incident, or heard about the incident after it occurred); who perpetrated the violence (including the gender of the perpetrator and the perpetrator's relationship to the child surveyed); and the child's reaction to the violent incident (including yelling at the perpetrator to stop, trying to get help, and hiding or leaving the scene). For more detailed information on individual questions, see "Screening Questions: Exposure to Intimate Partner Violence and Other Family Violence," p. 9.

\section{Limitations}

The survey methodology has several limitations that may cause it to understate children's actual exposure to violence. First, because the survey required the cooperation of the family, it ran the risk of missing those children who were most vulnerable to being exposed either to violence in general or to specific types of violence. Second, parents or caregivers who answer for younger children may not know about all of a child's exposure to violence or may underreport or minimize certain types of victimization. Third, the screening and followup questions may miss some episodes of victimization and incorrectly classify others. Fourth, children may not recall some exposure to violence, particularly less serious exposure, or may not accurately recall the timing of their exposure (i.e., whether or not the exposure occurred within the past year). The researchers note that although this survey, to their knowledge, includes the most questions ever asked about exposure to family violence in a nationally representative sample, these rates may not be comparable to rates obtained using longer questionnaires such as the Conflict Tactics Scales (Straus et al., 1996). Because of time limitations, the researchers collected incident data on only the most recent incident for each form of family violence. Despite these limitations, NatSCEV provides the most detailed and comprehensive data available on children's exposure to violence. 
Figure 1. Exposure to Physical Intimate Partner Violence

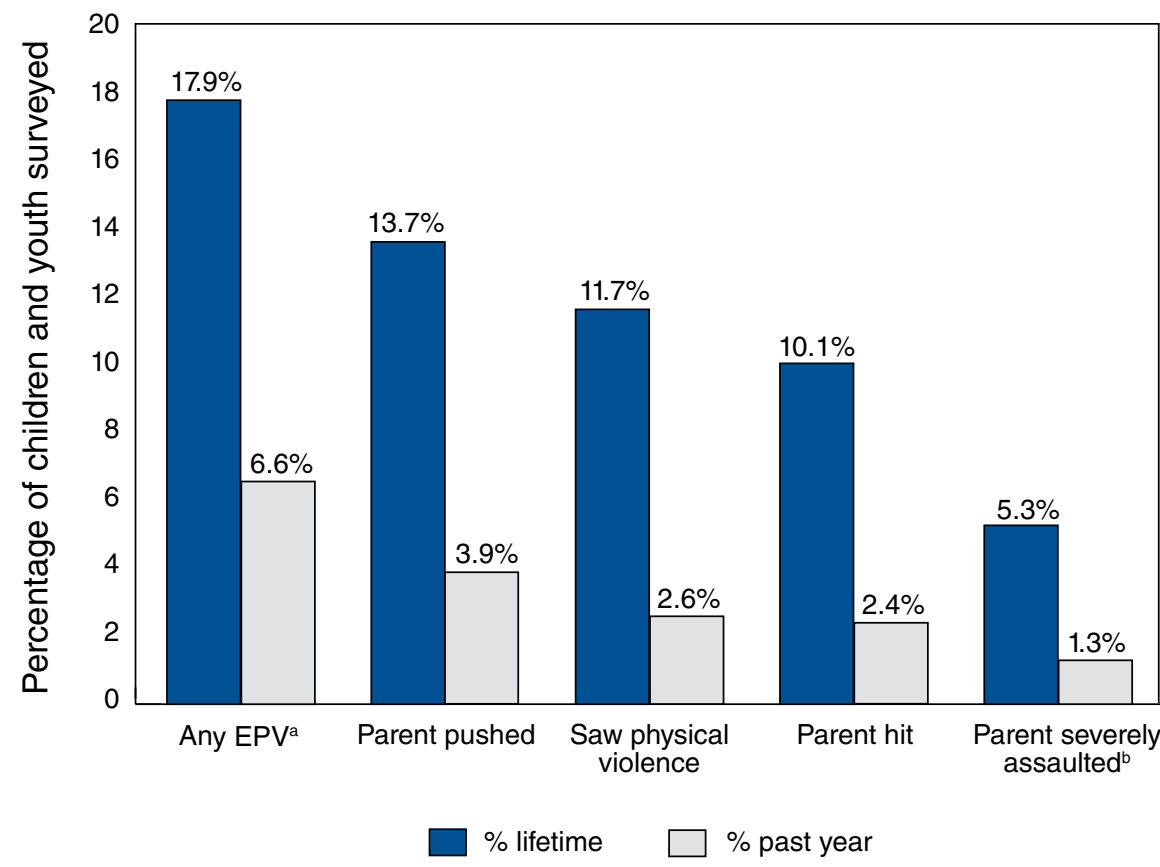

$E P V=$ Exposure to physical violence.

${ }^{a}$ Any EPV included any exposure to physical violence between intimate partners, including seeing, hearing, being told of the violence, or seeing the resulting injuries.

${ }^{b}$ Severe assault included one partner kicking, choking, or beating up the other.

Lifetime exposure percentages. Lifetime percentages were higher, reflecting the longer period of possible exposure. The lifetime percentage was 17.9 percent for exposure to physical IPV alone. Lifetime and past-year percentages for exposure to different types of physical IPV can be compared in figure 1 .

If, in addition to IPV exposure, parental assault of a sibling and violence between other teens and adults in the household are included, then lifetime exposure to physical or psychological violence within the family rises to 25.6 percent. As figure 2 shows, children are exposed to significant amounts of family violence other than IPV. A focus solely on IPV misses a substantial amount of the violence to which children are exposed.

These non-IPV incidents also were not infrequent. Among exposed youth, the mean number of lifetime exposures, aggregated across all screening questions, was 10.75 incidents (standard deviation $=21.22$ ), and the median was 3 incidents.

\section{Types of Children's Exposure to Family Violence}

Severity of exposure to family violence.

These are the first national data to characterize how children are typically exposed to violence in the family, and they show that most children who were exposed to family violence (IPV in particular) were eyewitnesses. The study assessed four different types of exposure in a hierarchical fashion from most to least direct: eyewitnessing or seeing the violence, hearing but not seeing it, seeing injuries afterwards but not seeing or hearing the actual assault, and being told about the violence without any of the above. The most immediate type of exposure, eyewitnessing, was by far the most common, accounting for 65 to 86 percent of all exposure. Other types of exposure nonetheless add significantly to the total, especially hearing but not seeing the violence.

Within this general pattern, however, there was some variation. Psychological aggression was more likely to be heard and not seen than physical aggression. Over their lifetimes, being told about family violence comprises a larger percentage of exposure (9.4 to 16.2 percent) for older youth (ages 10-17) than for younger children (4 to 7.6 percent for children ages 1 month to 9 years). Specifically, older children were more likely to be exposed to the following types of family violence by being told about them: exposure to verbal threats, displaced aggression, a family member being pushed, and a family member being hit or slapped. This same pattern was observed in past-year data; however, because of the smaller number of cases, it achieved significance only for displaced aggression. Youth's gender had no effect on the type of exposure.

Multiple types of exposure to family violence and eyewitnessing of family violence. Some youth may experience multiple types of exposure to family violence. For example, a youth could hear one act of violence (such as a verbal threat) and see another act (such as a slap). Although this youth would be coded at the "heard" level for verbal threat, he or she is also an eyewitness of IPV. To account for this, the researchers calculated lifetime percentages for eyewitnessing-the most direct exposure among those who reported exposure to a particular type of family violence: 72.7 percent of those exposed to psychological/emotional IPV were eyewitnesses, 90.1 percent of those exposed to physical IPV were eyewitnesses, and 87.1 percent of 
those exposed to other types of family violence were eyewitnesses. When youth are exposed to family violence, they usually witness at least some assaults. Nine out of ten children who were exposed to physical IPV in their lifetimes were eyewitnesses (see figure 3).

\section{Identification of Perpetrators of Family Violence}

Violence by intimate partners. Survey respondents were asked to identify the perpetrator's gender and relationship to the youth. Lifetime data are presented, as the patterns are very similar to past-year data and these include all available incidents. The report of gender was relatively straightforward. Modern family relationships, however, proved to be somewhat complex. Open-ended descriptions of perpetrators have been combined into four broad categories: "father," "mother," "other males," and "other females" (see figure 4). "Father" and "mother" include biological parents, adoptive parents, stepparents, foster parents, and cohabiting partners of any parents. The "other" categories include noncohabiting partners, caregiving relatives (e.g., grandparents), and occasional mentions of others in caregiving or parental roles, broadly construed, such as "godfather" or "foster mother's ex-husband" (to give specific examples). It is important to capture incidents involving all of these people to understand the true extent of children's exposure to family violence.

Males were identified as perpetrators in 78 percent of IPV incidents (with a range of 72 to 88 percent across different forms of IPV). The most severe violence (kicking, choking, or beating) had the highest percentage of male perpetrators (88 percent). Of specific perpetrator categories, fathers were the most commonly reported perpetrators, accounting for 61 to 71 percent of incidents involving males. The single largest category within "other males" was noncohabiting boyfriends of mothers, accounting for 45 to 76 percent of other males. The single largest category within "other females" was caregiving relatives such as grandmothers and aunts, accounting for 29 to 51 percent of other female perpetrators, although it should be noted that these were fairly rare reports-all other females together only accounted for about 5 percent of incidents.

\section{Figure 2. Percentages of Youth Exposed to Assault by Other Household Members}

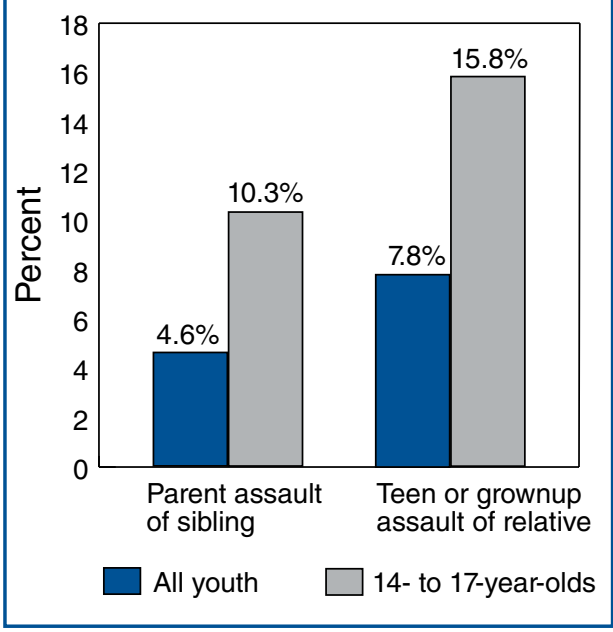

Figure 3. Percentages of Various Types of Exposure to Physical IPV

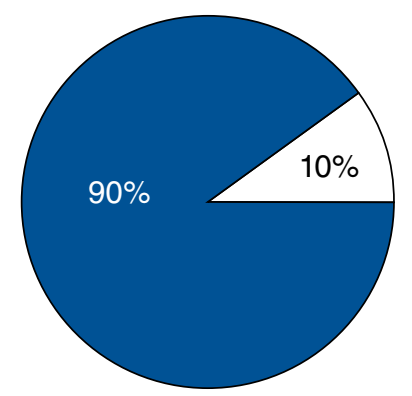

Eyewitness

Heard, saw, or was told about injuries

Aggregated perpetrator patterns for IPV incidents. A youth could be exposed to both male and female IPV perpetrators. For example, a youth might hear his or her father threaten his girlfriend and see his or her mother slap her ex-husband. This turned out to be infrequent, however. Of all youth exposed to IPV, most (68.8 percent) encountered only male IPV perpetrators. The next largest group (22.6 percent) consisted of those who described only female perpetrators, and few ( 8.6 percent) reported exposures to both male and female IPV perpetrators (see figure 5). In another indicator showing that both genders were seldom identified as perpetrators, the open-ended response of "both
Figure 4. Perpetrators of Family Violence in Front of Children

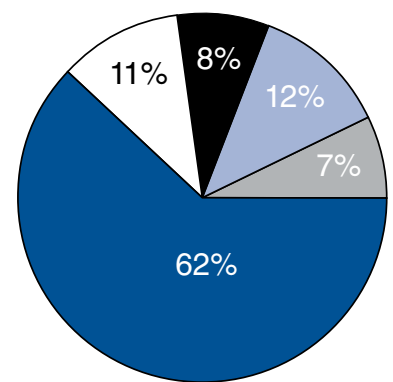

Perpetrator pattern for original Juvenile Victimization Questionnaire item on witnessing intimate partner violence

Father

$\square$ Mother

Boyfriend of mother Other males Other females

Figure 5. Perpetrator Patterns by Gender Across All IPV Incidents

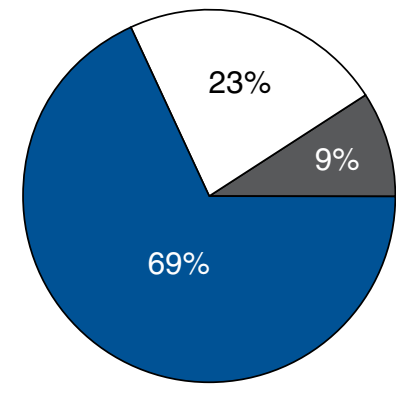

Males only $\square$ Females only Both

parents" was recorded only nine times, or in less than 1 percent of IPV incidents.

Perpetrators of other family violence. Fathers were again the most common perpetrators when a child witnessed the parental assault of a sibling, but the rate for mothers was somewhat higher than for IPV exposure. For other family violence that did not involve one parent's violence against the other parent or a sibling of the study participant, the largest proportion of the perpetrators were adolescent brothers, accounting for 56 percent of "other males" and 24 percent of the total. Fathers comprised a substantial portion of perpetrators (23 percent), mothers comprised 
10 percent, and all other females comprised 24 percent.

These findings align with most criminological data on IPV (Hamby, 2009; Snyder and McCurley, 2008) and are consistent with the "moderate asymmetry hypothesis" (Hamby, 2009), which indicates that males perpetrate most IPV and females perpetrate a substantial minority. It is also possible that youth are not true independent observers but are identifying the primary aggressor in ways that are influenced by the judgments of people calling the police or police officers making arrests (Snyder and McCurley, 2008). These findings nonetheless indicate how important it is to understand exposure to family violence from the child's perspective. Some children have many "parents"-biological parents, stepparents, adoptive parents, foster parents, and other caregivers-and it is clear that they are being exposed to violence perpetrated by a wide variety of caregivers and family members.

\section{Children's Reactions to Family Violence}

The information from the survey on children's reactions to violence by one parent against another indicates that large numbers were not simply passive observers, as shown in figure 6 . Almost one-half of the youth surveyed reported yelling to try to stop the violence or trying to get away from the violence: 49.9 percent of exposed youth had yelled at their parents to stop at least once, and 43.9 percent had tried to get away at least once (the range across individual IPV items was 34.2 to 65.7 percent for yelling at parents to stop and 36 to 47.5 percent for trying to get away). Calling for help was less prevalent but still fairly common at 23.6 percent or almost one in four youth (it ranged from 16.6 to 26.2 percent across individual forms of IPV).

Very similar reactions were also found to parental assaults of a sibling (49.3 percent yelled at the parent to stop, 41.6 percent tried to get away from the fighting, and 20.2 percent called for help) and violence between other household teens and adults (48.9 percent yelled, 30.3 percent tried to get away, and 26.1 percent called for help). These findings support clinical reports that children often yell at the perpetrators, try to get away, and call for help in response to family violence (Edleson, Shin, and Armendariz, 2008).

\section{Comparison of NatSCEV Findings With Previous Estimates of Exposure to Family Violence}

Exposure to family violence was common in this nationally representative sample of youth, with 1 in 9 (11 percent) reporting any exposure in the past year and 1 in 15 (6.6 percent) reporting exposure to physical violence between their parents (see table 1, p. 4). Extended to the entire U.S. youth population, this yields an estimate of approximately 8.2 million children and youth who were exposed to family violence in the past year alone. Lifetime exposures were even higher, already reaching 1 in 4 youth even in this fairly young sample, or 18.8 million children extrapolated to the population as a whole. Most of these exposures involved direct eyewitnessing (90 percent for IPV; 76 percent for other family violence). Approximately half of the youth yelled at their parents during a violent episode between the parents or tried to get away; nearly a quarter had called for help at least once (see figure 6).

The addition of more detailed questions in NatSCEV (see "Screening Questions: Exposure to Intimate Partner Violence and Other Family Violence," p. 9) resulted in estimates that are more than double the estimates from the earlier DVS survey (Finkelhor et al., 2005). The NatSCEV survey's 1-year point estimate is somewhat lower than that provided by McDonald and colleagues (2006), although the total lifetime estimates are considerably higher than those produced by other national surveys (Straus, 1992; Zinzow et al., 2009). Methodological factors probably account for these differences. McDonald and colleagues' (2006) analysis assumed that if IPV occurred in a household with children, the children were necessarily exposed to that violence, which would be unlikely given the private nature of some violence. The NatSCEV survey's higher lifetime estimates, compared to those of Straus (1992) and Zinzow and colleagues (2009), are probably due to assessing a wider array of violent acts and including more forms of possible exposure.

\section{Figure 6. Children's Immediate Responses to Violence Against Parents}

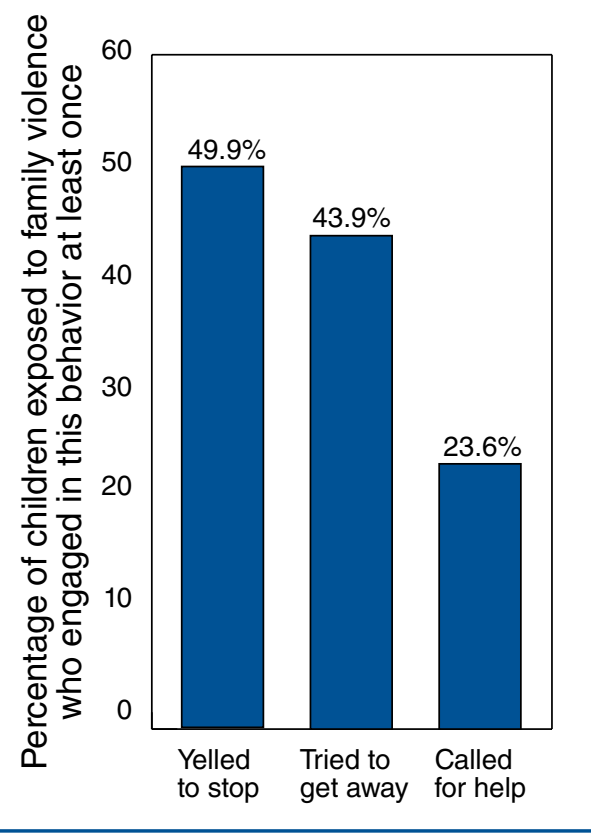

\section{Implications for Policymakers, Researchers, and Practitioners}

These comprehensive national estimates about children exposed to IPV and other family violence have several important ramifications. First, they provide a new, more scientifically grounded basis on which education, advocacy, and public policy can be advanced with authority and urgency. Second, they provide a baseline estimate using a sound and replicable methodology to monitor trends as professionals and policymakers attempt to reduce the toll of exposure to family violence. Third, they move the field toward a more systematic understanding of all types of exposure to IPV and other family violence.

Based on the epidemiology of exposure to family violence reflected in this research, several major public policy initiatives deserve consideration. These include:

- Better protocols to screen for children exposed to IPV and other family violence that can be used in many settings, including health care, education, mental health, family services, and the criminal justice system. 


\section{Screening Questions: Exposure to Intimate Partner Violence and Other Family Violence}

The National Survey of Children's Exposure to Violence (NatSCEV) used an enhanced version of the Juvenile Victimization Questionnaire (JVQ) (referred to as the JVQ-R1), an inventory that covers five general areas of youth victimization: conventional crime, maltreatment, victimization by peers and siblings, sexual victimization, and witnessing and indirect victimization (Finkelhor et al., 2005; Hamby, Ormrod, and Finkelhor, 2005). The original JVQ had two items on witnessing family violence; NatSCEV asked six more questions on the topic. The directions to the additional questions read, "The next set of questions are about people who have taken care of you [or 'your child,' substituted throughout] — that would include your parents, stepparents, and your 'parents' boyfriends or girlfriends, whether you lived with them or not. It would also include other grownups, like grandparents or foster parents if they took care of you on a regular basis. When we say 'parent' in these next questions, we mean any of these people."* If respondents reported family perpetrators and victims in response to other more general screeners, these episodes were also included in the rates.

\section{Questions Regarding Types of Exposure}

In the six new NatSCEV items regarding exposure to family violence, respondents were asked, "How did you know it happened?" The response options were: "Did you see it?"; "Did you hear it, but not see it?"; "Did you not see or hear it, but see the person's bruise or injury?"; and "Did you not see or hear anything, but someone told you?" Additional incident data were collected only for the first three types of exposure. Respondents were directed to describe the most recent episode of family violence that they saw, heard, or saw a resulting injury from.

\section{Questions Regarding Perpetrator Identity}

Respondents were asked, "Who did this?" Interviewers coded respondents' open-ended answers into several categories, including father, mother, sibling, other relative who lives with the youth, other relative who does not live with the youth, a parent's boyfriend or girlfriend, and other grownup. "Father" and "mother" included biological parents, adoptive parents, stepparents, and cohabiting partners of a parent. Responses that the interviewers could not categorize were recorded verbatim and coded later.

Fathers were recorded as males, mothers as females. If the perpetrator's gender was not clear, respondents were asked, "Was this a man, woman, boy, or girl?"

\section{Questions Regarding Reactions to Incidents of Family Violence}

Three questions based on the Child Exposure to Domestic Violence scale (Edleson, Shin, and Armendariz, 2008) were asked: "When this happened, did you yell at them to stop?"; "When this happened, did you call someone else for help, like calling someone on the phone or going next door?"; and "When this happened, did you try to get away from the fighting by hiding or leaving the house?" The last two questions were asked only about youth age 2 and older. These questions were asked only of respondents who first described these incidents during the family violence portion of the interview (not if the episode was disclosed in response to one of the more general screening questions).

* For the exact wording of the questions, see Finkelhor, Turner, Ormrod, and Hamby, 2009.

- Improved interventions to assist exposed children, particularly those who have been exposed to the most severe forms of violence or who experience chronic exposure to violence. These interventions could include safety planning that is targeted at children's safety, and evidence-based therapeutic programs to help children cope with their exposure (Graham-Bermann et al., 2007). school-based education, parenting education, and public awareness campaigns.

These new findings offer some guidance on issues that these protocols and programs should address. Perhaps most importantly, protocols and programs need to recognize that exposure to violence occurs in a wide array of family relationships. In today's society, many children have more than two parents, and assessments should be sure to document exposures to noncustodial parents, stepparents, boyfriends or girlfriends of parents, and other in-home caregivers (such as grandparents). Likewise, NatSCEV provides the strongest available data so far to indicate that children are witnessing violence between other family members, and this exposure should also be addressed. Evidence showing that nearly all exposed children are direct eyewitnesses to at least some violence in the home provides new urgency to longstanding calls to continue working on model protocols and programs.

\section{Endnotes}

1. The DVS, a precursor to NatSCEV, asked a nationally representative sample of 2,030 children ages 10 to 17 and caregivers of children ages 2 to 9 about their past-year exposure to crime and violence in five categories: conventional crime, child maltreatment, peer and sibling victimization, sexual assault, and witnessing and indirect victimization. The DVS was the first national survey to estimate the incidence of witnessing physical abuse (Finkelhor et al., 2005; Kracke and Hahn, 2008).

\section{Because mothers' noncohabiting boy-} friends constitute such a large proportion of perpetrators of IPV that children are exposed to (11 percent, versus 8 percent for all other males in the "other males" category), they are broken out into a separate category in figure 4 .

\section{References}

Acierno, R., Resnick, H., Kilpatrick, D.G., and Stark-Riemer, W. 2003. Assessing elder victimization-Demonstration of a methodology. Social Psychiatry and Psychiatric Epidemiology 38(11):644-653.

Association for the Study and Development of Community. 2005. National Evaluation of the Safe Start Demonstration Project, January Through December 2004, Volume 1: Cross-Site Process Evaluation. Gaithersburg, 


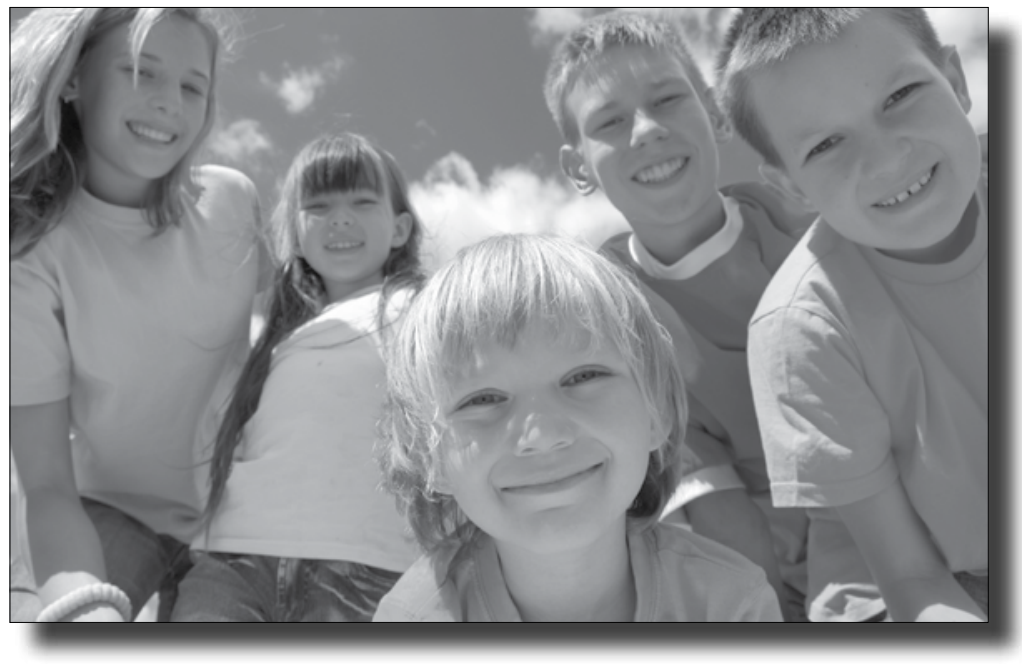

MD: Association for the Study and Development of Community.

Bolen, R.M., and Scannapieco, M. 1999. Prevalence of child sexual abuse: A corrective meta-analysis. Social Services Review 73(3):281-313.

Edleson, J.L., Shin, N., and Armendariz, K. 2008. Measuring children's exposure to domestic violence: The development and testing of the Child Exposure to Domestic Violence (CEDV) Scale. Children and Youth Services Review 30:502-521.

Fantuzzo, J., Boruch, R., Beriama, A., Atkins, M., and Marcus, S. 1997. Domestic violence and children: Prevalence and risk factors in five major U.S. cities. Journal of the American Academy of Child and Adolescent Psychiatry 36(1):116-122.

Fantuzzo, J., and Mohr, W.K. 1999. Prevalence and effects of child exposure to domestic violence. The Future of Children 9(3):21-32.

Finkelhor, D., Turner, H., Ormrod, R., and Hamby, S.L. 2005. The victimization of children and youth: A comprehensive, national survey. Child Maltreatment 10(1):5-25.

Finkelhor, D., Turner, H.A., Ormrod, R.K., and Hamby, S.L. 2009. Violence, crime, and exposure in a national sample of children and youth. Pediatrics 124(5):1411-1423.

Finkelhor, D., Turner, H., Ormrod, R., Hamby, S., and Kracke, K. 2009. Children's Exposure to Violence: A Comprehensive National Survey. Washington, DC: U.S. Department of Justice, Office of Justice
Programs, Office of Juvenile Justice and Delinquency Prevention.

Graham-Bermann, S.A., Lynch, S., Banyard, V., DeVoe, E.R., and Halabu, H. 2007. Community-based intervention for children exposed to intimate partner violence: An efficacy trial. Journal of Consulting and Clinical Psychology 75(2):199-209.

Grych, J.H. 1998. Children's appraisals of interparental conflict: Situational and contextual influences. Journal of Family Psychology 12:437-453.

Hamby, S.L. 2009. The gender debate on intimate partner violence: Solutions and dead ends. Psychological Trauma 1(1):2434 .

Hamby, S.L., Ormrod, R., and Finkelhor, D. 2005. Victim gender, perpetrator gender and victim-offender relationship in a nationally representative study of youth victimization. Paper presented at the Ninth International Family Violence Research Conference, Portsmouth, NH, July 10-13.

Holden, G.W. 2003. Children exposed to domestic violence and child abuse: Terminology and taxonomy. Clinical Child and Family Psychology Review 6(3):151-160.

Hutchison, I.W., and Hirschel, J.D. 2001. The effects of children's presence on woman abuse. Violence and Victims 16(1):3-17.

Jaffe, P.G., Crooks, C.V., and Wolfe, D.A. 2003. Legal and policy responses to children exposed to domestic violence: The need to evaluate intended and unintended consequences. Clinical Child and Family Psychology Review 6(3):205-219.
Jouriles, E.N., and Norwood, W.D. 1995. Physical aggression toward boys and girls in families characterized by the battering of women. Journal of Family Psychology 9:69-78.

Kitzmann, K.M., Gaylord, N., Holt, A., and Kenny, E. 2003. Child witnesses to domestic violence: A meta-analytic review. Journal of Consulting and Clinical Psychology 71(2):339-352.

Kracke, K., and Hahn, H. 2008. The nature and extent of childhood exposure to violence: What we know, why we don't know more, and why it matters. Journal of Emotional Abuse 8(1/2):29-49.

Lang, J.M., and Stover, C.S. 2008. Symptom patterns of youth exposed to intimate partner violence. Journal of Family Violence 23:619-629.

McDonald, R., Jouriles, E.N., RamisettyMikler, S., Caetano, R., and Green, C.E. 2006. Estimating the number of children living in partner-violent families. Journal of Family Psychology 20(1):137-142.

Murrell, A.R., Merwin, R.M., Christoff, K.A., and Henning, K.R. 2005. When parents model violence: The relationship between witnessing weapon use as a child and later use as an adult. Behavior and Social Issues 14:128-133.

National Domestic Violence Hotline. 1998. Safety planning. Available online at: www. thehotline.org/get-help/safety-planning.

Nixon, K.L., Tutty, L.M., Weaver-Dunlop, G., and Walsh, C.A. 2007. Do good intentions beget good policy? A review of child protection policies to address intimate partner violence. Children and Youth Services Review 29:1469-1486.

Schechter, S., and Edleson, J.L. 1999. Effective Intervention in Domestic Violence and Child Maltreatment: Guidelines for Policy and Practice. Reno, NV: National Council of Juvenile and Family Court Judges.

Shannon, E.E., Mathias, C.W., Marsh, D.M., Dougherty, D.M., and Liguori, A. 2007. Teenagers do not always lie: Characteristics and correspondence of telephone and in-person reports of adolescent drug use. Drug and Alcohol Dependence 90(2-3): 288-291.

Snyder, H.N., and McCurley, C. 2008. Domestic Assaults by Juvenile Offenders. Washington, DC: U.S. Department of Justice, Office of Justice Programs, Office of Juvenile Justice and Delinquency Prevention. 
Straus, M.A. 1992. Children as witness to marital violence: A risk factor for lifelong problems among a nationally representative sample of American men and women. In Children and Violence: Report of the Twenty-Third Ross Roundtable on Critical Approaches to Common Pediatric Problems, edited by D.F. Schwarz. Columbus, OH: Ross Laboratories, pp. 98-104.

Straus, M.A., and Gelles, R.J. 1990. Physical Violence in American Families: Risk Factors and Adaptations to Violence in 8,145 Families. New Brunswick, NJ: Transaction Publishers.

Straus, M.A., Hamby, S.L., Boney-McCoy, S., and Sugarman, D.B. 1996. The Revised
Conflict Tactics Scales (CTS2). Journal of Family Issues 17:283-316.

Tjaden, P., and Thoennes, N. 1998. Prevalence, Incidence, and Consequences of Violence Against Women: Findings from the National Violence Against Women Survey. Washington, DC: U.S. Department of Justice, Office of Justice Programs, National Institute of Justice.

Wolfe, D.A., Crooks, C.V., Lee, V., McIntyreSmith, A., and Jaffe, P.G. 2003. The effects of children's exposure to domestic violence: A meta-analysis and critique. Clinical Child and Family Psychology Review 6(3):171-187.

Zinzow, H.M., Ruggiero, K.J., Resnick, H., Hanson, R., Smith, D., Saunders, B., and
Kilpatrick, D. 2009. Prevalence and mental health correlates of witnessed parental and community violence in a national sample of adolescents. Journal of Child Psychology and Psychiatry 50(4):441-450.

\section{For Further Information}

To learn more about the Safe Start Initiative, visit www.safestartcenter.org.

For more information about the National Survey of Children's Exposure to Violence, visit the Crimes Against Children Research Center Web site at www.unh.edu/ccrc. Detailed supplementary tables of the rates reported here can be obtained by contacting Sherry Hamby at sherry.hamby@ sewanee.edu.

\section{Acknowledgments}

This bulletin was written by Sherry Hamby, Ph.D., Research Associate Professor, Department of Psychology, Sewanee: The University of the South; David Finkelhor, Ph.D. Director, Crimes Against Children Research Center, University of New Hampshire; Heather Turner, Ph.D., Professor, Crimes Against Children Research Center, University of New Hampshire; and Richard Ormrod, Ph.D., Research Professor, Crimes Against Children Research Center, University of New Hampshire. OJJDP wishes to acknowledge the contributions to this bulletin of Rebecca T. Leeb, Ph.D., Epidemiologist, Division of Violence Prevention, National Center for Injury Prevention and Control, Centers for Disease Control and Prevention (CDC). OJJDP also wishes to acknowledge the support of CDC for the National Survey of Children's Exposure to Violence and its partnership in the Safe Start Initiative to create safe, stable, and nurturing environments for children and their families.

\section{Share With Your Colleagues}

Unless otherwise noted, OJJDP publications are not copyright protected. We encourage you to reproduce this document, share it with your colleagues, and reprint it in your newsletter or journal. However, if you reprint, please cite OJJDP and the authors of this bulletin. We are also interested in your feedback, such as how you received a copy, how you intend to use the information, and how OJJDP materials meet your individual or agency needs. Please direct your comments and questions to:

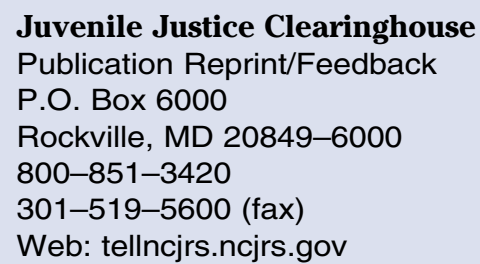

This bulletin was prepared under cooperative agreement number 2005-JL-FX-0048 from the Office of Juvenile Justice and Delinquency Prevention (OJJDP), U.S. Department of Justice.

Points of view or opinions expressed in this document are those of the authors and do not necessarily represent the official position or policies of OJJDP or the U.S. Department of Justice.

The Office of Juvenile Justice and Delinquency Prevention is a component of the Office of Justice Programs, which also includes the Bureau of Justice Assistance; the Bureau of Justice Statistics; the National Institute of Justice; the Office for Victims of Crime; and the Office of Sex Offender Sentencing, Monitoring, Apprehending, Registering, and Tracking. 


\section{U.S. Department of Justice}

Office of Justice Programs

Office of Juvenile Justice and Delinquency Prevention

Washington, DC 20531

Official Business

Penalty for Private Use $\$ 300$ 